\title{
The effect of heating insufflation gas on acid-base alterations and core temperature during laparoscopic major abdominal surgery
}

\author{
Kyung-Cheon Lee ${ }^{1}$, Ji Young Kim², Hyun-Jeong Kwak ${ }^{1}$, Hee-Dong Lee ${ }^{1}$, and Il Won Kwon ${ }^{2}$ \\ Department of Anesthesiology and Pain Medicine, ${ }^{1}$ Gachon University of Medicine and Science, Incheon, \\ ${ }^{2}$ Yonsei University College of Medicine, Seoul, Korea
}

Background: Carbon dioxide $\left(\mathrm{CO}_{2}\right)$ has different biophysical properties under different thermal conditions, which may affect its rate of absorption in the blood and the related adverse events. The present study was aimed to investigate the effects of heating of $\mathrm{CO}_{2}$ on acid-base balance using Stewart's physiochemical approach, and body temperature during laparoscopy.

Methods: Thirty adult patients undergoing laparoscopic major abdominal surgery were randomized to receive either room temperature $\mathrm{CO}_{2}$ (control group, $\mathrm{n}=15$ ) or heated $\mathrm{CO}_{2}$ (heated group, $\mathrm{n}=15$ ). The acid-base parameters were measured $10 \mathrm{~min}$ after the induction of anesthesia (T1), $40 \mathrm{~min}$ after pneumoperitoneum (T2), at the end of surgery (T3) and $1 \mathrm{~h}$ after surgery (T4). Body temperature was measured at 15-min intervals until the end of the surgery.

Results: There were no significant differences in $\mathrm{pH}, \mathrm{PaCO}_{2}$, the apparent strong ion difference, the strong ion gap, bicarbonate ion, or lactate between two groups throughout the whole investigation period. At T2, pH was decreased whereas $\mathrm{PaCO}_{2}$ was increased in both groups compared with $\mathrm{Tl}$ but these changes were not significantly different. Body temperatures in the heated group were significantly higher than those in the control group from 30 to 90 min after pneumoperitoneum.

Conclusions: The heating of insufflating $\mathrm{CO}_{2}$ did not affect changes in the acid-base status and $\mathrm{PaCO}_{2}$ in patients undergoing laparoscopic abdominal surgery when the ventilator was set to maintain constant end-tidal $\mathrm{CO}_{2}$. However, the heated $\mathrm{CO}_{2}$ reduced the decrease in the core body temperature $30 \mathrm{~min}$ after the pneumoperitoneum.

(Korean J Anesthesiol 2011; 61: 275-280)

Key Words: Acid-base balance, Heated $\mathrm{CO}_{2}$, Laparoscopy.

Received: February 11, 2011. Revised: 1st, March 18, 2011; 2nd, April 16, 2011. Accepted: April 26, 2011.

Corresponding author: Hyun-Jeong Kwak, M.D., Department of Anesthesiology and Pain Medicine, Gil Medical Center, 1198, Guwol-dong, Namdong-gu, Incheon 405-760, Korea. Tel: 82-32-460-3637, Fax: 82-32-469-6319, E-mail: hyun615@gilhospital.com

(c) This is an open-access article distributed under the terms of the Creative Commons Attribution Non-Commercial License (http:// creativecommons.org/licenses/by-nc/3.0/), which permits unrestricted non-commercial use, distribution, and reproduction in any medium, provided the original work is properly cited. 


\section{Introduction}

Laparoscopic surgery has been replacing a variety of complex intra-abdominal procedures. However, the increased complexity of laparoscopic surgery requires much longer pneumoperitoneum time and this raises concerns about the adverse effects of prolonged gas insufflations such as cardiovascular, respiratory and renal disturbances caused by a direct increase in intra-abdominal pressure and sympathetically mediated vasoconstriction $[1,2]$.

Carbon dioxide $\left(\mathrm{CO}_{2}\right)$ is widely used to create the pneumoperitoneum because it is a colorless, odorless and noninflammable gas that dissolves rapidly in case of gas embolism $[3,4]$. This easy absorption of $\mathrm{CO}_{2}$ also results in hypercarbia, which in turn stimulates sympathetic nervous system and causes respiratory acidosis. As with any other gases, $\mathrm{CO}_{2}$ has different biophysical properties under different thermal conditions, which may affect the rate of absorption in the blood and related adverse events. In an experimental study using pigs, Bashirov et al. [5] have reported that when $\mathrm{CO}_{2}$ pneumoperitoneum was applied under the same pressure, the changes in $\mathrm{PaCO}_{2}$ were directly proportional to and the changes in $\mathrm{pH}$ were inversely proportional to the temperature of the insufflated $\mathrm{CO}_{2}$. They also reported that significant differences in core body temperature changed between heated gas group and room temperature gas group [5].

Since clinical data regarding the effects of heated $\mathrm{CO}_{2}$ on acid-base changes during the prolonged pneumoperitoneum are limited, the present study investigated the effects of heating the insufflation $\mathrm{CO}_{2}$ on body temperature and acidbase balance using Stewart's physiochemical approach during the laparoscopic major abdominal surgery. Stewart's physiochemical approach was used to analyze the acid base alteration in this study because the traditional approaches by the Henderson-Hasselbalch equation are often inadequate to explain the complexity of acid-base derangements during laparoscopic surgery [6-8].

\section{Materials and Methods}

After procedure approval of the institutional review board, thirty adult patients undergoing major abdominal surgery gave informed consent and were studied prospectively. Using sealed envelopes, patients were randomized to receive either $\mathrm{CO}_{2}$ gas at room temperature $\left(22^{\circ} \mathrm{C}\right.$; control group, $\left.\mathrm{n}=15\right)$ or normothermic heated $\left(37^{\circ} \mathrm{C}\right)$ gas (heated group, $\left.n=15\right)$. The gas was warmed using the WISAP Flow Therme (WISAP, Germany). This study included laparoscopic major abdominal surgeries expecting a pneumoperitoneum time longer than 90 minutes such as gastrectomy, colectomy or low anterior resection. The pneumoperitoneum was applied at a level of $12-15 \mathrm{mmHg}$ of pressure. Room temperature was maintained at $23-24^{\circ} \mathrm{C}$ in both groups. An upper body blanket was applied to all patients and when the core temperature of a patient fell below $35.0^{\circ} \mathrm{C}$, a Bair Hugger forced air warmer (Augustine Medical Inc, MN, USA) and a warming mattress with circulating water at $38^{\circ} \mathrm{C}$ were applied. The exclusion criteria were body mass index greater than $30 \mathrm{~kg} / \mathrm{m}^{2}$, chronic renal failure, respiratory insufficiency, and preexisting metabolic acidosis.

The patients were premedicated with intramuscular injection of midazolam ( $2 \mathrm{mg}$ ) and glycopyrrolate $(0.2 \mathrm{mg}), 1$ $\mathrm{h}$ before induction of anesthesia. On arrival in the operating room, routine anesthetic monitors were attached. Anesthesia was induced with propofol, remifentanil and rocuronium. Lungs were ventilated with a tidal volume of $7-10 \mathrm{ml} / \mathrm{kg}$ and, a respiratory rate of $8-12$ breaths/ $\mathrm{min}$, to maintain an endtidal carbon dioxide tension $\left(\mathrm{ETCO}_{2}\right)$ of $30-35 \mathrm{mmHg}$ at a $60 \%$ inspired oxygen with air. The tidal volume and respiratory rate were readjusted to maintain an $\mathrm{ETCO}_{2}$ between $35-40 \mathrm{mmHg}$ after pneumoperitoneum in both groups. After the induction, a $20 \mathrm{G}$ catheter was inserted into the radial artery for continuous arterial pressure monitoring and blood sampling, and a central venous catheter was inserted through the right jugular vein for central venous pressure monitoring. Hartmann's solution and $6 \%$ hydroxyethyl starch in normal saline (NS) solution (Voluven ${ }^{\mathrm{TM}}$, Fresenius Kabi, Bad Homberg, Germany) were administered. Packed red blood cells were transfused when hemoglobin fell below $8 \mathrm{~g} / \mathrm{dl}$. All infusion fluids were not warmed. Draping was standardized and warmed $\left(38^{\circ} \mathrm{C}\right)$ irrigation fluid was used.

Hemodynamic variables, $\mathrm{ETCO}_{2}$, and temperatures were continuously monitored and recorded at 5-minute intervals using Datex-Ohmeda $\mathrm{S} / 5^{\mathrm{TM}}$ Collect software (GE Healthcare, Helsinki, Finland). Core body temperature was measured with an esophageal stethoscope and esophageal temperature probe (DeRoyal Inc., Powell, TN, USA) after anesthetic induction (baseline) and at 15-min intervals until completion of surgery. Body temperature was also measured in the postanesthesia care unit (PACU), using a tympanic thermometer (ThermoScan IRT 1020, Braun, Germany). In PACU, Bair Hugger forcedair warmer was applied to those patients with tympanic temperature below $36^{\circ} \mathrm{C}$.

In order to evaluate acid-base balance, the blood samples were taken at $10 \mathrm{~min}$ after the induction of anesthesia (T1), 40 min after pneumoperitoneum (T2), at the end of surgery (T3), and $1 \mathrm{~h}$ after the surgery (T4). The arterial blood samples were measured for $\mathrm{pH}, \mathrm{PaCO}_{2}$ (standard electrodes), and serum lactate ( $\mathrm{Lac}^{-}$; enzymatic method, quantification of $\mathrm{H}_{2} \mathrm{O}_{2}$ ), using a blood gas analyzer (GEM Premier 3000, Instrumentation Laboratory, MA, USA). Standard base excess (SBE) and 
bicarbonate ion $\left(\mathrm{HCO}_{3}{ }^{-}\right)$were calculated from the blood gas analyzer, which uses the Henderson-Hasselbalch equation. Additionally, the concentrations of sodium $\left(\mathrm{Na}^{+}\right)$, potassium $\left(\mathrm{K}^{+}\right)$, chloride $\left(\mathrm{Cl}^{-}\right)$(ion-selective electrode), serum phosphate ( $\mathrm{Pi}^{-}$; ultraviolet photometry of a phosphomolybdate complex), and serum total albumin (Alb; colorimetry of bromocresol complex) were measured using the same blood sample. The apparent strong ion difference (SIDa) was calculated using the formula [9]: SIDa $=\left[\mathrm{Na}^{+}\right]+\left[\mathrm{K}^{+}\right]-\left[\mathrm{Cl}^{-}\right]-$Lactate $]$. The effective strong ion difference (SIDe) was calculated using the formula: $\mathrm{SIDe}=12.2 \times \mathrm{pCO}_{2} /\left(10^{-\mathrm{pH}}\right)+10 \times$ [albumin $] \times(0.123 \times$ $\mathrm{pH}-0.631)+\left[\mathrm{Pi}^{-}\right] \times(0.309 \times \mathrm{pH}-0.469)$. The strong ion gap (SIG) was calculated by subtracting the SIDe from the SIDa: SIG $=$ SIDa - SIDe.

Based on a previous study [6], a sample size of 12 patients per group was calculated to demonstrate a mean difference in $\mathrm{pH}$ of 0.06 with an expected SD of 0.05 , using values of $\alpha=$ 0.05 with a power (1- $\beta$ ) of $80 \%$. In order to compensate for an estimated dropout rate of $25 \%, 15$ patients for each group were recruited.

Statistical analyses were performed with SPSS 13.0 (SPSS Inc, Chicago, IL, USA). Data are expressed as mean \pm SD or number of patients. Data between the groups were compared by using an independent t-test. Changes between time points within the group were compared using repeated measures of univariate analysis of variance (ANOVA) with post hoc comparisons using the Dunnett's test. A P value $<0.05$ was considered statistically significant.

\section{Results}

There were no significant differences in patient characteristics between the two groups (Table 1). No surgery was converted to open laparotomy in each group. Hemodymic parameters are summarized in Table 2. During the study period, mean arterial pressure, heart rate and central venous pressure

Table 1. Patients Characteristics and Operation Profiles

\begin{tabular}{lcc}
\hline & Control (n=15) Heated (n=15) \\
\hline Age (yr) & $55.1 \pm 11.4$ & $60.1 \pm 8.6$ \\
Weight (kg) & $57.8 \pm 7.4$ & $63.1 \pm 9.4$ \\
Height (cm) & $163.9 \pm 9.3$ & $163.4 \pm 5.8$ \\
Body surface area $\left(\mathrm{m}^{2}\right)$ & $1.61 \pm 0.13$ & $1.69 \pm 0.15$ \\
Sex (M/F) & $9 / 6$ & $10 / 5$ \\
Medical history (n) & 3 & 6 \\
$\quad$ Hypertension & 3 & 3 \\
$\quad$ Diabetes mellitus & & \\
Operation (n) & $8 / 4 / 3$ & $8 / 3 / 4$ \\
Low anterior resection/colectomy/gastrectomy & $230 \pm 67$ & $212 \pm 67$ \\
Operation time (min) & $268 \pm 70$ & $242 \pm 63$ \\
Anesthesia time (min) & $158 \pm 59$ & $122 \pm 43$ \\
Pneumoperitoneum time (min) & & \\
Fluid balance, intraoperative (ml) & & \\
$\quad$ Crystalloid & $1,300[900-1,600]$ & $1,200[900-1,900]$ \\
$\quad$ Colloid & $600[400-750]$ & $700[500-1,000]$ \\
Urine output, intaoperative & $232[138-365]$ & $195[105-340]$ \\
Estimated blood loss & $300[200-500]$ & $300[200-500]$ \\
\hline
\end{tabular}

Values are mean \pm SD or number of patients or median [interquartile range]. Control: patients with unheated $\mathrm{CO}_{2}$, Heated: patients with heated $\mathrm{CO}_{2}$. There were no significant differences between the two groups.

Table 2. Hemodynamic Parameters

\begin{tabular}{llcccc}
\hline & & T1 & T2 & T3 & T4 \\
\hline MAP (mmHg) & Control & $96 \pm 17$ & $87 \pm 10$ & $88 \pm 10$ & $95 \pm 18$ \\
& Heated & $98 \pm 20$ & $89 \pm 8$ & $89 \pm 13$ & $93 \pm 14$ \\
HR (beats/min) & Control & $75 \pm 13$ & $67 \pm 11$ & $64 \pm 15$ & $83 \pm 15$ \\
CVP (mmHg) & Heated & $75 \pm 14$ & $62 \pm 10^{*}$ & $62 \pm 13^{*}$ & $82 \pm 12$ \\
& Control & & $12.8 \pm 4.3$ & $9.0 \pm 3.7$ & $8.5 \pm 3.4$ \\
& Heated & & $10.8 \pm 2.3$ & $8.9 \pm 4.2$ & $7.9 \pm 2.7$ \\
\hline
\end{tabular}

Values are mean \pm SD. Control:patients with unheated $\mathrm{CO}_{2}$, Heated: patients with heated $\mathrm{CO}_{2}$. MAP: mean arterial pressure, HR: heart rate, CVP: central venous pressure, T1: $10 \mathrm{~min}$ after anesthesia induction, T2: $40 \mathrm{~min}$ after the insufflations of $\mathrm{CO}_{2}$, T3: at the end of surgery, T4: 60 min after the post-anesthetic care unit arrival. ${ }^{*} \mathrm{P}<0.05$ vs. baseline values (T1) within the group. 
were comparable between the two groups.

The changes of acid-base status are illustrated in Fig. 1. At T2, pH was decreased and $\mathrm{PaCO}_{2}$ was increased in both groups when compared to $\mathrm{T} 1$, although these changes were not statistically insignificant. Compared with T1, SIDa and $\mathrm{HCO}_{3}{ }^{-}$were decreased at T2, T3 and T4 in both groups except for $\mathrm{HCO}_{3}{ }^{-}$in the control group at T2. SIG and lactate were not changed in both groups during the study period. There were
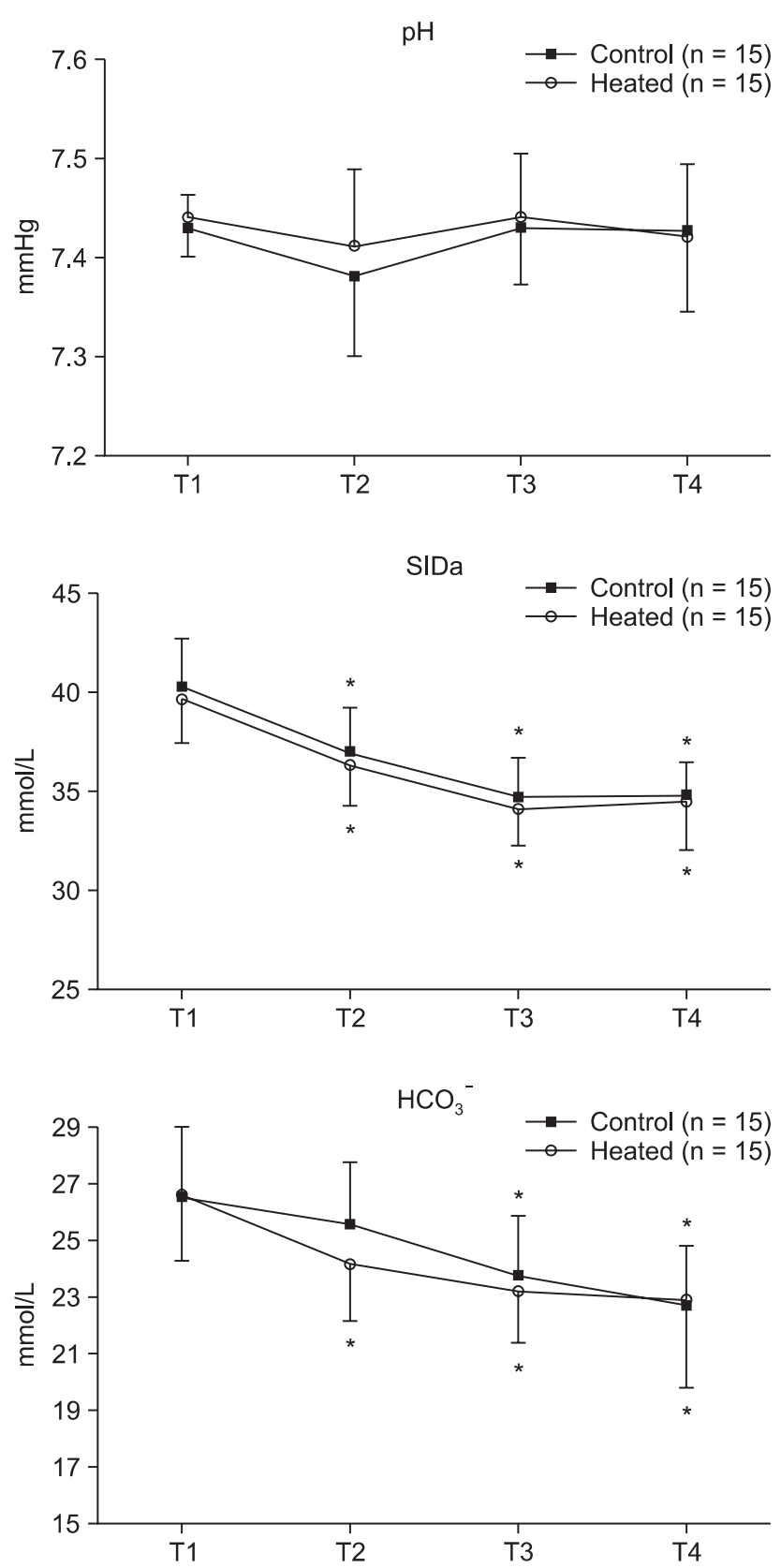

no significant differences in $\mathrm{pH}, \mathrm{PaCO}_{2}$, SIDa, SIG, $\mathrm{HCO}_{3}{ }^{-}$ and lactate between the two groups throughout the whole investigation period.

The changes of body temperature are summarized in Fig. 2. Compared with baseline values, core temperatures were significantly decreased from $30 \mathrm{~min}$ and $60 \mathrm{~min}$ after pneumoperitoneum in the control and the heated groups, respectively. However, the body temperatures in the heated
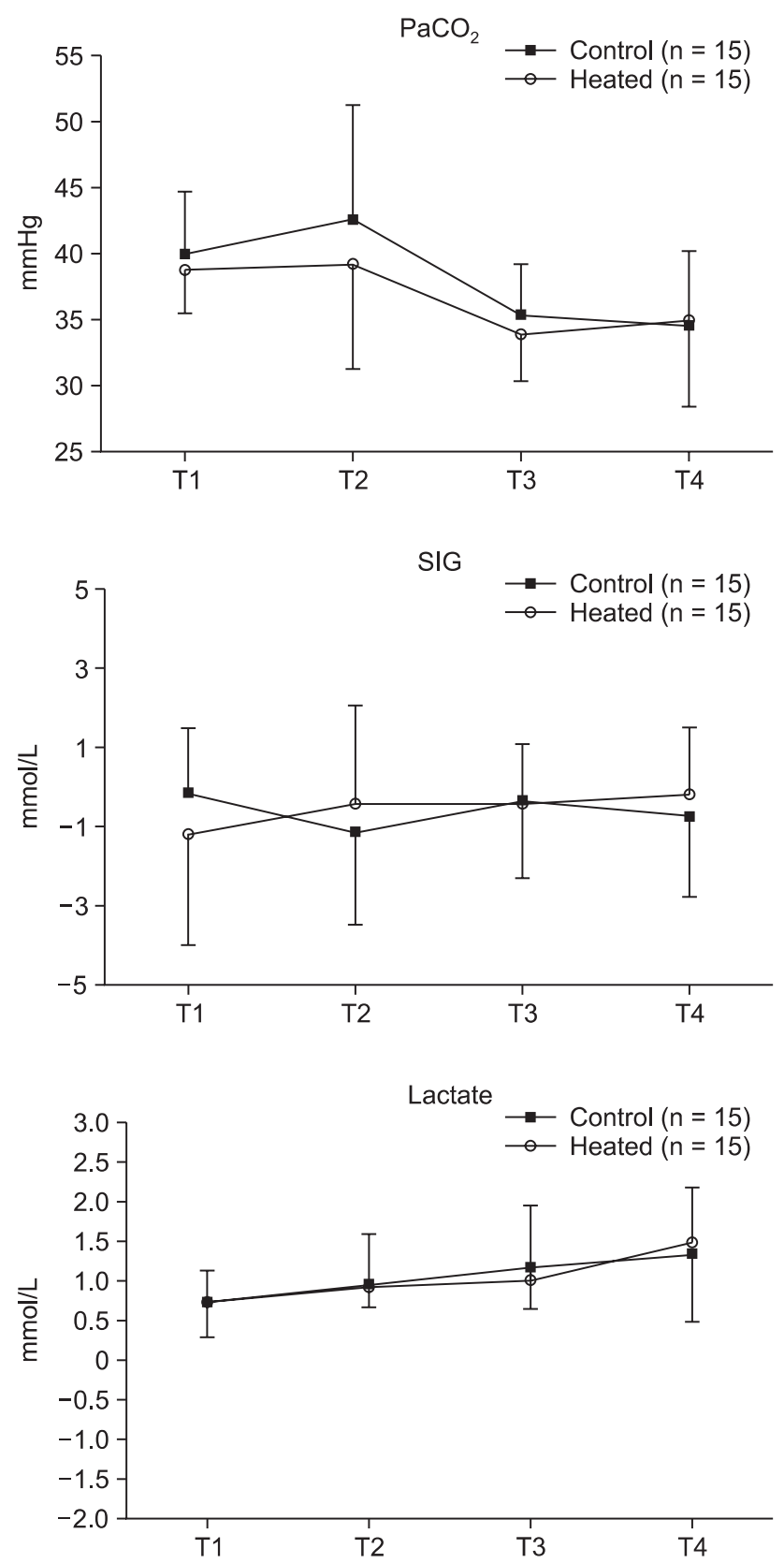

Fig. 1. Changes in acid-base status of patients undergoing laparoscopic major abdominal surgery. Filled squares indicate the control group; open circles, the heated group. Values are mean \pm SD. T1: $10 \mathrm{~min}$ after the induction of anesthesia, T2: 40 min after pneumoperitoneum, T3: at the end of the surgery, T4: $1 \mathrm{~h}$ after the surgery, SIDa: apparent strong ion difference, SIG: strong ion gap. *P $<0.05$ vs. baseline values (T1) within the group. 


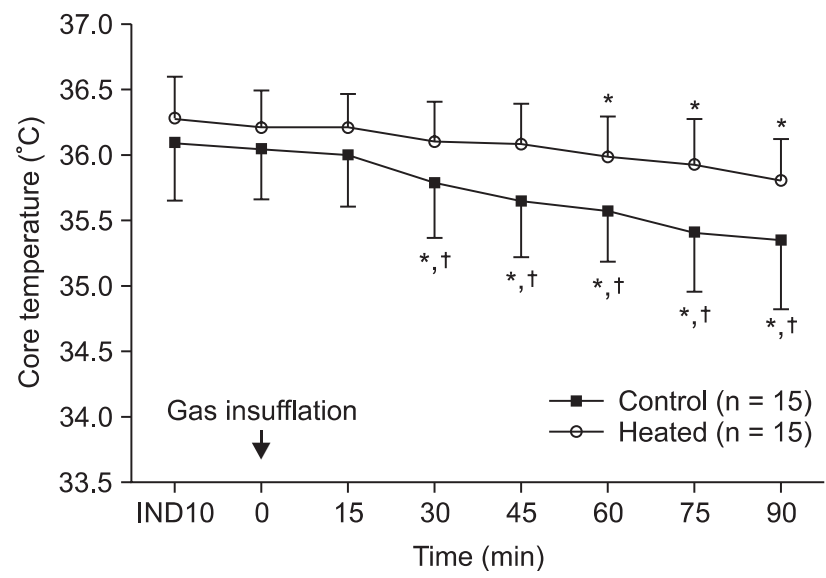

Fig. 2. Changes in core body temperature of patients undergoing laparoscopic major abdominal surgery. Filled squares indicate the control group; open circles, the heated group. Values are mean \pm SD. T1: $10 \mathrm{~min}$ after the induction of anesthesia, T2: $40 \mathrm{~min}$ after pneumoperitoneum, T3: at the end of the surgery, T4: $1 \mathrm{~h}$ after the surgery, IND10: $10 \mathrm{~min}$ after anesthesia induction. ${ }^{*} \mathrm{P}<0.05$ vs. baseline values (IND10) within the group, ${ }^{\dagger} \mathrm{P}<0.05$ vs. control group.

group were significantly higher than those in the control group at $30,45,60,75$, and $90 \mathrm{~min}$ after pneumoperitoneum $(\mathrm{P}=$ $0.028,0.004,0.002,0.002$, and 0.012 , respectively). Tympanic membrane temperatures in PACU were $36.3 \pm 0.39^{\circ} \mathrm{C}$ and $36.1 \pm$ $0.72^{\circ} \mathrm{C}$ in the control and heated groups, respectively and which was not differrent $(\mathrm{P}=0.461)$. The temperature data at $105 \mathrm{~min}$ were not shown because the core temperature of 4 patients in each group fell below $35^{\circ} \mathrm{C}$ and Bair Hugger forced air warmer and a warming mattress with circulating water were applied.

\section{Discussion}

In the present study, there were no significant differences in the acid-base variables including $\mathrm{PaCO}_{2}$ between the two groups in patients undergoing laparoscopic major abdominal surgery. However, the heating of insufflating $\mathrm{CO}_{2}$ reduced the decrease of the core body temperature during prolonged pneumoperitoneum.

The effect of $\mathrm{CO}_{2}$ pneumoperitoneum on acid-base balance remains controversial. Some experimental and clinical studies have demonstrated risks of acid-base changes during $\mathrm{CO}_{2}$ pneumoperitoneum toward metabolic acidosis [7,10]. Another investigation reported that $\mathrm{CO}_{2}$ pneumoperitoneum causes alterations in acid-base balance, mostly of the respiratory or mixed type [11]. In the present study, blood $\mathrm{pH}$ was decreased in conjunction with an increase in $\mathrm{PaCO}_{2}$ during $\mathrm{CO}_{2}$ pneumoperitoneum, although these changes were not statistically significant. After desufflation, the $\mathrm{pH}$ increased with a decrease in $\mathrm{PaCO}_{2}$ in both groups. These results suggest that the decrease in the $\mathrm{pH}$ during the pneumoperitoneum was affected by the increase in $\mathrm{PaCO}_{2}$, which promptly returned to a normal value after the desufflation. On the other hand, after the surgery, pHs in both groups slightly decreased with significant decreases in SID, suggesting metabolic factors. In addition, in the present study, a significant within-group change was not observed in unmeasured, unidentified cations or anions as assessed by calculating the SIG in both groups. Therefore, the metabolic factor of the decreased $\mathrm{pH}$ after surgery may have been influenced by the reduction of SID, which may have resulted from the water excess or hyperchloremia.

During $\mathrm{CO}_{2}$ pneumoperitoneum, the pressure and temperature of the gas are the two main factors that directly influence the absorption rate. Assuming that the $\mathrm{CO}_{2}$ pressure is constant throughout the pneumoperitoneum, the influence of the gas temperature on the diffusion and absorption rates could be explained from both physical and physiologic perspectives $[5,12]$. From the physical perspective, the relationship between the diffusion coefficient (D) and heat could be hypothesized using Fick's diffusion law [12]; $\mathrm{D}=k_{B} \mathrm{~T} / \mathrm{f}$, where $\mathrm{T}$ is the absolute temperature, $f$ is the friction coefficient, and $k_{B}$ is the Boltzman constant $(1.38 \times 10-23 \mathrm{~J} / \mathrm{K})$. Heating of the $\mathrm{CO}_{2}$ may increase its absorption rate from the peritoneum, and does the risk of hypercapnia and acidosis. From the physiologic perspective, the peritoneal perfusion and permeability of the peritoneal vessels may increase with heating, which may result in easy pulmonary elimination of absorbed $\mathrm{CO}_{2}$ through venous and lymphatic microcirculation [5].

In their study, Bashirov et al. [5] demonstrated that $\mathrm{CO}_{2}$ insufflated at $7^{\circ} \mathrm{C}$ caused a less evident increase in $\mathrm{PaCO}_{2}$ and a less evident reduction in blood $\mathrm{pH}$ than $\mathrm{CO}_{2}$ insufflated at $22^{\circ} \mathrm{C}$ and $37^{\circ} \mathrm{C}$. They concluded that the heating of $\mathrm{CO}_{2}$ could increase the risk of hypercapnia and acidosis by accelerating its absorption [5]. However, in the present study, the changes in $\mathrm{pH}$ and $\mathrm{PaCO}_{2}$ did not differ between the two groups receiving warm $\left(37^{\circ} \mathrm{C}\right)$ and room temperature $\left(22^{\circ} \mathrm{C}\right)$ gas. This may have been attributed to readjustment of the respiratory rate during the pneumoperitoneum. If the respiratory rate were fixed after the gas insufflation as in the experimental study by Bashirov et al. [5], the change in $\mathrm{CO}_{2}$ and $\mathrm{pH}$ may have been greater in the heated group. As a result, hypercapnia should have caused an elevation of blood pressure, tachycardia and arrhythmia, which is deleterious especially when the pneumoperitoneum is prolonged. One limitation of our study was the inclusion of several types of surgery, necessitating different positions. Since different positions may affect the hemodynamics, further study may be needed to elucidate the effect of position on acid-base alteration during pneumoperitoneum.

In the present study, the body temperature was significantly higher in the heated than in the control group from $30 \mathrm{~min}$ 
after the insufflations with $\mathrm{CO}_{2}$. The effects of warming the insufflation $\mathrm{CO}_{2}$ on intraoperative core temperature in experimental and clinical studies have been controversial [1216]. Experimental studies using pigs and rats demonstrated that the heating and humidifying of gas may prevent laparoscopic hypothermia $[13,14]$. However, other studies in humans reported that the heating of insufflation $\mathrm{CO}_{2}$ does not affect intraoperative core temperature $[17,18]$. Nguyen et al. [17] used an external warming blanket in both groups and reported the increase in core temperature at $90 \mathrm{~min}$ after surgical incision. In addition, in the study by Davis et al. [18], the operation time was only about $80 \mathrm{~min}$, which is quite shorter than ours (212-230 min). Therefore, the significant difference in changes of body temperature between the groups may have resulted from longer operation time and thus a longer insufflation time, and a lack of an external warming device use in the present study.

In conclusion, the use of heated insufflation $\mathrm{CO}_{2}$ did not affect the acid-base status and $\mathrm{PaCO}_{2}$ in patients undergoing laparoscopic major abdominal surgery when the ventilator was set to maintain constant end-tidal $\mathrm{CO}_{2}$. However, the heated $\mathrm{CO}_{2}$ reduced the decreases in body temperature $30 \mathrm{~min}$ after the pneumoperitoneum.

\section{References}

1. Schachtrupp A, Toens Ch, Hoer J, Klosterhalfen B, Lawong AG, Schumpelick V. A 24-h pneumoperitoneum leads to multiple organ impairment in a porcine model. J Surg Res 2002; 106: 37-45.

2. Taura P, Lopez A, Lacy AM, Anglada T, Beltran J, Fernandez-Cruz $\mathrm{L}$, et al. Prolonged pneumoperitoneum at $15 \mathrm{mmHg}$ causes lactic acidosis. Surg Endosc 1998; 12: 198-201.

3. Menes T, Spivak H. Laparoscopy: searching for the proper insufflation gas. Surg Endosc 2000; 14: 1050-6.

4. Gebhardt H, Bautz A, Ross M, Loose D, Wulf H, Schaube H. Pathophysiological and clinical aspects of the $\mathrm{CO}_{2}$ pneumoperitoneum (CO2-PP). Surg Endosc 1997; 11: 864-7.

5. Bashirov E, Cetiner S, Emre M, Seydaliyeva T, Alic V, Daglioglu K, et al. A randomized controlled study evaluating the effects of the temperature of insufflated $\mathrm{CO}_{2}$ on core body temperature and blood gases (an experimental study). Surg Endosc 2007; 21: 1820-5.
6. Kwak HJ, Jo YY, Lee KC, Kim YB, Shinn HK, Kim JY. Acid-base alterations during laparoscopic abdominal surgery: a comparison with laparotomy. Br J Anaesth 2010; 105: 442-7.

7. Gándara V, de Vega DS, Escriú N, Zorrilla IG. Acid-base balance alterations in laparoscopic cholecystectomy. Surg Endosc 1997; 11: 707-10.

8. Story DA, Kellum JA. New aspects of acid-base balance in intensive care. Curr Opin Anaesthesiol 2004; 17: 119-23.

9. Fencl V, Leith DE. Stewart's quantitative acid-base chemistry: applications in biology and medicine. Respir Physiol 1993; 91: 1-16.

10. Shuto K, Kitano S, Yoshida T, Bandoh T, Mitarai Y, Kobayashi M. Hemodynamic and arterial blood gas changes during carbon dioxide and helium pneumoperitoneum in pigs. Surg Endosc 1995; 9: 1173-8.

11. Sefr R, Puszkailer K, Jagos F. Randomized trial of different intraabdominal pressures and acid-base balance alterations during laparoscopic cholecystectomy. Surg Endosc 2003; 17: 947-50.

12. Pattabhi V. The physico-chemical techniques to study molecules. In: Biophysics. Edited by Pattabhi V, Gautham N: New Delhi, Narosa Publishing House. 2002, pp 37-40.

13. Bessell JR, Ludbrook G, Millard SH, Baxter PS, Ubhi SS, Maddern GJ. Humidified gas prevents hypothermia induced by laparoscopic insufflation: a randomized controlled study in a pig model. Surg Endosc 1999; 13: 101-5.

14. Hazebroek EJ, Schreve MA, Visser P, De Bruin RW, Marquet RL, Bonjer HJ. Impact of temperature and humidity of carbon dioxide pneumoperitoneum on body temperature and peritoneal morphology. J Laparoendosc Adv Surg Tech A 2002; 12: 355-64.

15. Gray RI, Ott DE, Henderson AC, Cochran SA, Roth EA. Severe local hypothermia from laparoscopic gas evaporative jet cooling: a mechanism to explain clinical observations. JSLS 1999; 3: 171-7.

16. Nelskylä K, Yli-Hankala A, Sjöberg J, Korhonen I, Korttila K. Warming of insufflation gas during laparoscopic hysterectomy: effect on body temperature and the autonomic nervous system. Acta Anaesthesiol Scand 1999; 43: 974-8.

17. Nguyen NT, Furdui G, Fleming NW, Lee SJ, Goldman CD, Singh A, et al. Effect of heated and humidified carbon dioxide gas on core temperature and postoperative pain: a randomized trial. Surg Endosc 2002; 16: 1050-4.

18. Davis SS, Mikami DJ, Newlin M, Needleman BJ, Barrett MS, Fries R, et al. Heating and humidifying of carbon dioxide during pneumoperitoneum is not indicated: a prospective randomized trial. Surg Endosc 2006; 20: 153-8. 